\title{
EVOLUTIONARY PATHS AND INFLUENCING FACTORS TOWARDS DIGITAL MATURITY: AN ANALYSIS OF THE STATUS QUO IN SWISS HOSPITALS
}

Tobias Mettler, Institut de hautes études en administration publique, University of Lausanne, Rue de la Mouline 28, 1022 Chavannes-près-Renens, Switzerland, e-mail: tobias.mettler@unil.ch Roberto Pinto, Department of Management, Information and Production Engineering, University of Bergamo, Viale Marconi 5, 24044 Dalmine, Italy, e-mail: roberto.pinto@unibg.it

Citation: Mettler T, Pinto R. Evolutionary paths and influencing factors towards digital maturity: An analysis of the status quo in Swiss hospitals. Technological Forecasting \& Social Change. forthcoming; https://doi.org/

Objective: The purpose of this study is to discuss the term 'digital maturity' based on the evidence emerging from an extensive longitudinal investigation. Further, this study provides evidence regarding evolutionary paths, influencing factors, and improvement potentials in hospitals.

Materials and Methods: Based on a comprehensive multi-year (2008-2014) data set obtained from a previously developed benchmarking and maturity assessment tool, we conducted exploratorydescriptive and path analyses to detect structural patterns and alternative explanations for the digital maturity of Swiss hospitals ( $\mathrm{n}=35)$.

Results: Digital maturity is a relative and subjective construct that either improves or worsens over time, is bound to perceptions of health professionals, and seldom reaches a final stage. We found that hospitals have a strong internal focus, and that digitalization is conducted in a reactive way. Since digital maturity is constantly in flux, the health information technology (HIT) appraisal of hospitals suffers from temporal variances due to several factors, such as enhancements in the eco-system, changes in the user base, or unforeseen/unprepared system adaptations.

Conclusion: Although there are different ways to influence the perceived digital maturity of a hospital, the most promising way is to invest in hardware and software because investments in personnel development or enhancements of operations and maintenance services did not show a significant relation. In conclusion, digital maturity is a hospital's organizational asset that needs to be maintained and nurtured over time.

Keywords: Electronic health record systems; digital maturity; health information technology planning; health information technology assessment; maturity model 


\section{INTRODUCTION}

Government agencies as well as public and private healthcare providers have operated under the assumption that investments into health information technology (HIT) usually translate into favorable outcomes in terms of increased quality of medicine (Bates \& Gawande, 2003; Miller et al., 2005), greater productivity (Eastaugh, 2012; Thouin et al., 2008), and cost reduction of health administration (Cutler et al., 2012; Hillestad et al., 2005). Building upon this premise, U.S. Congress appropriated almost U.S. $\$ 20$ billion for facilitating the implementation of electronic health record systems (United States Congress, 2009). Likewise, in Western Europe the modernization of the healthcare sector will generate a growth in HIT spending from U.S. $\$ 13.2$ billion in 2013 to U.S. \$14.6 billion in 2018 (IDC, 2015).

While these budgets reflect high hopes, there have also been contradictory voices proclaiming that healthcare is facing the "productivity paradox" (Devaraj \& Kohli, 2000; Hebert, 1998; Jones et al., 2012; Lapointe et al., 2011), a phenomenon which has previously been observed in the manufacturing industry describing an overall negative correlation between productivity and IT investments (Brynjolfsson, 1993). A growing number of studies have therefore been dedicated to seek the real impacts of digitizing healthcare on quality of care, costs, and work processes (Chaudhry et al., 2006; Sabherwal \& Jeyaraj, 2015; Williams et al., 2017) and to offer explanations for this paradoxical observation (Kohli \& Grover, 2008; Thatcher \& Pingry, 2007). In the face of the digitalization of ever more areas of our private and business lives, however, the question whether to invest into HIT or not seems to be ill-defined. Instead, it would be all the more important for decision-makers to have a concise understanding of the current situation, for example to know which technologies are 'white spots' (i.e. missing or poorly adopted) in the hospital's HIT architecture. Second, although productivity certainly is important, also other relevant aspects of healthcare may be enhanced by digitized services, such as patient safety (Kaelber \& Bates, 2007), well-being (Luxton et al., 2011), empowerment (Samoocha et al., 2010), or other soft factors which are hard to measure. Consequently, the measure 'digital maturity', broadly intended as a measure of how well an entity - in our case, a hospital - is making use of digital technology to attain better performance, is often used as proxy for capturing the overall impacts of HIT, particularly on the quality of health services delivery (Flott et al., 2016). 
Although consultants and technologists, frequently without substantial facts, describe

healthcare as 'lagging behind' in the race toward fully digitized industries (Gandhi et al., 2018), we would omit such a generalization and take the discussion to a different direction, rather focusing on the clarification of 'digital maturity' as a concept and its function as decision aid for the enhancement of a local, or even regional or national HIT architecture. With this paper, we seek therefore to obtain a more in-depth understanding of the evolutionary paths and influencing factors towards digital maturity. Particularly, the following research questions will be explored in this study: (a) what is digital maturity in the context of hospitals, (b) how can digital maturity pragmatically be assessed, and (c) what can be learned from a longitudinal perspective?

To answer these questions, we first clarify our understanding of the two concepts HIT and digital maturity by providing a review of the extant literature. In the next section, we then render the necessary contextual background and explanations concerning our hypotheses, study variables, and analysis procedures. Based on empirical findings, we then discuss the main influencing factors towards digital maturity and provide possible explanations for different evolutionary paths. We conclude by highlighting the practical contributions of our study and their implications for continued research in the area of maturity assessments in healthcare.

\section{BACKGROUND}

\subsection{A definition of health information technology and scope of this study}

Literature dealing with the investigation of IT productivity and digital maturity in healthcare frequently entails a high-level understanding of HIT. In fact, the HIT literature spans many disciplines and adopts various standpoints for defining its purpose and scope. Most frequently, HIT is referred to as "[...] medical IT-applications for facilitating the management and delivery of healthcare" (Pagliari et al., 2005), such as for storage and exchange of clinical data (e.g. electronic medical records, electronic health records), inter-professional communication (e.g. secure e-mail and direct messaging), computer-based support (e.g. clinical decision support systems, computerized physician order entry), patient-provider interaction and service delivery (e.g. patient referral and handover systems), and education (e.g. surgery simulators). To a 
lesser extent, existing literature also considers the crucial administrative role of HIT, for instance, as a facilitator of revenue increases (Mindel \& Mathiassen, 2015) or for lowering the bureaucratic burden (Abraham et al., 2011).

Most research implicitly ties HIT with the use in primary care (e.g. family doctors, medical specialists), secondary care (e.g. hospitals, clinics), or medical research facilities. However, due to overall changes in the availability of and interaction with technology (Wang et al., 2018), some authors propose to take a broader view considering systems that may be used beyond care and research facilities as a means for community-based health promotion and policy making (Mettler \& Raptis, 2012; Sarkar et al., 2011). Notwithstanding this broad definition, in this paper, we focus our attention on systems that are used in the hospital environment for the support of both medical and administrative operations. We do so because (i) most studies related to the productivity paradox concentrate on hospital IT investments as it often captures the largest share of governmental HIT spending (Agarwal et al., 2010; Kohli et al., 2012) and (ii) previous efforts in hospitals have been fraught with difficulty and failure (Waring, 2015). To our view, it is therefore a reasonable starting point for developing a more contextually nuanced view on HIT (Chiasson \& Davidson, 2004).

\subsection{Digital maturity and the different simultaneously existing notions of the digital hospital}

Like the divergent conceptualization of HIT, there is also no commonly agreed definition for the concept of 'digital maturity'. Maturity can be generally described as the "state of being complete, perfect, or ready" (Simpson \& Weiner, 1989). However, since technology continuously evolves and in seldom cases reaches a stage of ultimate perfection, we put forward to comprehend digital maturity as a relative concept with regard to both the surrounding working environment and time. In fact, the digital maturity of a hospital usually evolves and changes over time (i.e. thanks to new hardware and software acquisitions or dismantling) and place (i.e. from one site to another) (Gastaldi et al., 2018). Digital maturity is therefore a "learned" characteristic of an entity that represents its ability to respond to the environment in an appropriate manner (Kane et al., 2017). In this respect, digital maturity is the result of a continuous and ongoing process of adaptation to a changing digital landscape. 
Anticipating the results of our literature analysis, we consider digital maturity as a subjective concept, describing to which extent stakeholders perceive that their work environment shows high uptake of electronic services and/or provides contemporary support for their tasks. To explore this relativity and subjectivity, and to better understand extant connotations and meanings of the concept, we searched PubMed, ISI, and Scopus for published articles in the last 25 years (1990-2015) conceptualizing "digital maturity" and/or containing "digital hospital" as central topic (see Figure 1; for a detailed list of reviewed articles see Appendix A).

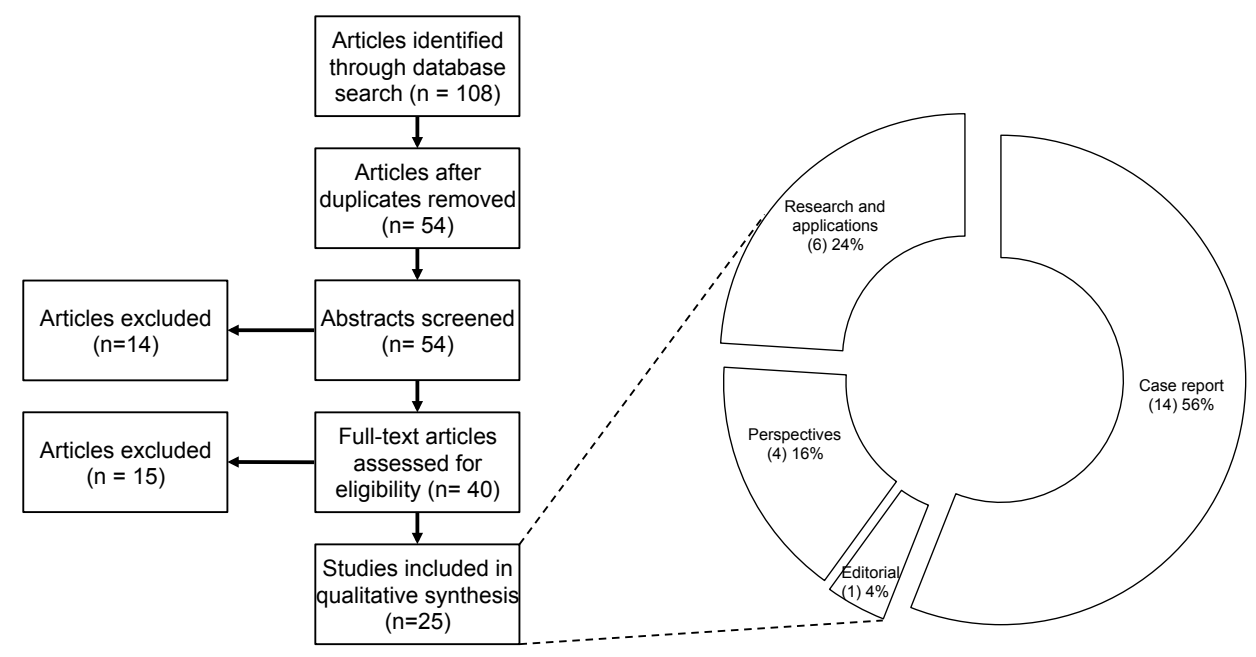

Figure 1. Flow diagram and types of articles related to digital hospitals.

We included peer-reviewed articles describing new research and applications, as well as nonreviewed case reports, editorials, and perspectives papers written in the English language. As of August 2016, our search yielded 108 articles out of which 54 were duplicates. After screening the titles and abstracts of the remaining 54 articles, we excluded 14 papers, and after reading the full-texts another 15 papers were excluded, because there was no clear relation to either digitalization in healthcare or the hospital environment. Based on an abductive analysis approach (Tavory, 2016), we identified four different, simultaneously existing notions of digital maturity in the context of hospitals, which are summarized in Table 1 and which we detail next.

Not surprisingly, almost a third of the reviewed articles (28\%) recognize digitalization as the transition from paper to electronic methods of working in hospitals (e.g. replacement of paper- 
based radiology equipment by digital imaging and archiving solutions). Following the understanding in these papers (Baldwin, 2009; Burbridge \& Bell, 2004; Habal, 2004; HewlettPackard Company, 2006; Hruby et al., 1992; Hruby et al., 1996; Kramer, 2006), a high level of digital maturity is reached when a hospital can be run (almost) entirely paperless or where great part of the interaction between different stakeholders (e.g. physicians, administrative personnel, patients) is facilitated by a digital medium.

Most papers (44\%), however, go beyond this notion of a digitally mature hospital and emphasize the importance of standardized and integrated services (i.e. data and process integration). Based on the majority of publications (Chang et al., 2003; Gao et al., 2011; Jeong et al., 2015; King et al., 2003; Li \& Gao, 2014; Lu et al., 2005; Pavlopoulos \& Delopoulos, 1999; Peng et al., 2000; Ricke \& Bartelink, 2000; Weiss, 2002; Yoo et al., 2014), not only the mere existence of HIT (e.g. picture archiving and communication system, laboratory information system) characterizes a high digital maturity, but also the level of integration, data quality, and adherence to governance principles within the hospital.

In some articles (16\%) these aforementioned conceptualizations are criticized because of a too strong focus on health professionals, respectively the negligence of comprehending digitalization as an opportunity for improving the experience of patients. Therefore, not only digital services for improving the working conditions of health professionals, but also HIT that supports and innovates the patient care process is needed (e.g. with respect to patient safety, privacy, and self-determination) (Lacanna, 2013; Mockler \& Dologite, 2006; Pierre, 2004; Rollins, 2002). In this sense, digital maturity can be understood as the degree to which a hospital is able to harness technology for a better patient experience.

Finally, a small proportion of papers (12\%) emphasize the fact that digitalization also has to be seen from an infrastructure point of view. With today's smart and networked technology, a fusion of the "physical" with the "digital" is possible, which offers fundamentally new ways how to run and organize a hospital (Coile, 2003; Mullaney \& Weintraub, 2005; Yoo et al., 2012). It is hard to say what digital maturity in the context of these papers means. Most probably, a digitally mature hospital can be characterized by a combination of previous understandings, however, emphasizing not only the existence of new digital services but more 
importantly also hardware components which are fully integrated in the hospitals HIT architecture.

In conclusion, this discussion highlights the difficulties in finding an unequivocal and commonly accepted way to define, measure and assess digital maturity (DM) in different contexts (or different hospitals like in our case). Companies mature in different ways, at different paces, and along different directions as they learn how to respond appropriately to and how to better exploit - the emerging digital competitive environment. Therefore, in our study we define digital maturity as the perceived level of appropriateness of HIT services to respond to the patients' and regulators' needs for an efficient and effective health service delivery, and to support the hospitals' operators in implementing these demands. In this regard, we relied on a subjective assessment provided by the HIT users regarding their perceived contribution from HIT services in delivering appropriate performance, making use of technology to transition from paper-based to paperless processes, integrate data and processes, and provide higher quality care services (see Appendix C for a description of the operationalization of constructs).

Table 1. Conceptualizations of digital maturity in the hospital context.

\begin{tabular}{ll}
\hline Conceptualization of digital maturity & Characteristics of a digital hospital \\
\hline a) Digital maturity understood as change from & Hospitals that work (almost) paperless and/or which \\
paper-based to digital working styles in hospitals & stakeholders communicate exclusively by electronic means \\
b) Digital maturity understood as embodiment of & Hospitals that facilitate seamless exchange of information \\
extensive data and process integration in & and/or which stakeholders interoperate without media \\
hospitals & breaks \\
c) Digital maturity understood as graduator for & Hospitals that offer exceptional digital patient experience \\
innovation related to the patient care process & and/or similar to what is known and usual in other \\
& industries \\
d) Digital maturity understood as fusion of & Hospitals that successfully operate and harness the \\
physical and digital infrastructure components & potentials of a smart and networked HIT infrastructure
\end{tabular}




\section{EXPLORING THE LINK BETWEEN DIGITAL MATURITY AND HIT INVESTMENTS}

The review of the extant literature showed that different conceptualizations of digital maturity exist, which in turn lead to dissimilar views on what comprises a "digital hospital" in today's healthcare market. As already underlined, this certainly impedes a universal measurement of this phenomenon, which probably has led to a stronger focus of current research on the effects of financial investments in HIT and its implications for hospitals (Mettler, 2016; Meyer \& Degoulet, 2010; Salzberg et al., 2012). However, first evidence suggests that digital maturity, implicitly or explicitly, is influenced by two factors: digital intensity and transformation management intensity of an organization (Westerman et al., 2012).

Based on Westerman et al. (2012), we define digital intensity (DI) as the share of investments allocated for purchasing new hardware and software solutions (HS) as well as for improving operations and maintenance (OM) of existing digital services. Using a ratio instead of absolute amounts allows us to compare hospitals of different sizes. In doing so, we establish a link between digital maturity and HIT investments, which allows for a pragmatic assessment of a hospital's level of digital maturity, regardless of the chosen mental model of involved stakeholders. According to this understanding of digital maturity and digital intensity, we formulate the following hypotheses:

Hypothesis 1: Investments in new hardware and software (HS) have a positive effect on the digital maturity (DM) of a hospital.

Hypothesis 2: Investments in better operations and maintenance (OM) services have a positive effect on the digital maturity (DM) of a hospital.

Put in other words, by formulating hypothesis 1 we assume that although newer hardware and software might not lead directly to a productivity increase (see previous discussion on the IT productivity paradox), it nonetheless leads to a positive shift in the perception among health professionals because HIT may modernize their working style and/or quality of their work environment. With hypothesis 2 we suppose that investments in operations and maintenance, such as outsourcing and contracting by professional service providers, may have a similar positive effect on the perception of end-users. 
Following Westerman et al. (2012), we define transformation management intensity as the share of spending allocated for advancing the digital transformation in organizations as well as for creating the necessary IT-leadership capabilities within the workforce. Transformation management intensity relates mainly to internal personnel development (PD) at all levels of the organization. Indeed, staff and managers might be inclined to move to other employers if they feel they do not have the right opportunities to develop their digital skills (Kane et al., 2017). We therefore posit the following hypothesis:

Hypothesis 3: Investments in IT personnel development (PD) have a positive effect on the digital maturity (DM) of a hospital.

With hypothesis 3 we act on the assumption that increasing the IT literacy among health professionals (e.g. by means of vocational trainings and other forms of learning) may reduce negative attitudes towards using HIT and ultimately results in a more positive perception about the digital maturity of the hospital. This is in line with various studies, which observed that particularly the lack of IT knowledge among health professionals is holding up progress (Meade et al., 2009; Murphy et al., 2004).

Lastly, there is firm evidence that positive user perceptions and expectations manifest in increased usage intensity (UI) (Agarwal \& Prasad, 1998; Bhattacherjee \& Hikmet, 2007), defined as the perceived level of the HIT pervasiveness of the hospital's activities and processes; a high usage intensity underpins an ubiquitous presence of HIT services supporting both patient care and administrative processes. We therefore aim to test the following hypothesis:

Hypothesis 4: High levels of digital maturity (DM) have a positive effect on usage intensity (UI).

With this last hypothesis, we try to capture the possible positive effects of digital maturity, or in other words, to validate the assumption that higher levels of digital maturity also lead to higher usage within an organization. 


\section{METHODS}

\subsection{Data collection and setting}

As shown in Figure 2, starting point for this project was the Swiss e-health strategy announced in 2007, which implicitly demanded a massive leap forward in terms of digitalization in the years to come. However, at that time, policy-making and collective actions set in motion to implement the strategy were not considering the actual state of digital maturity in hospitals, respectively did not deal with the fact that it could be possible that hospitals were not ready to cope with the upcoming challenges regarding the switchover from a physical to a predominantly digital working environment. Practical instruments that could provide a contextspecific overview—at least of some extent—of the hospitals' state of digital maturity did not exist. However, in the literature we found exemplary benchmarks and maturity grids (Jahn \& Winter, 2011; Liebe \& Hübner, 2013; Peng et al., 2014; Waring, 2015) that provided a basis for studying digital maturity in the hospital. Benchmarks are based on (quantitative) performance indicators for measuring the degree to which an organization is able to efficiently and effectively exploit their IT capabilities and resources (Otieno et al., 2008), maturity grids are rather (qualitative) conceptual multistage models that either describe typical patterns in the development of organizational capabilities or compare the current state of IT capabilities and resources against some notional 'best' or 'desired' state (Mettler, 2011).

In 2008 , to collect the necessary data for measuring the perceived digital maturity in hospitals as well as for testing our hypotheses, we developed an online analytics platform combining both a quantitative benchmark with a qualitative maturity grid regarding the perceived level of appropriateness of HIT services (see Appendix D). The benchmark is used for obtaining cost estimations (based on the annual financial accounting reports) regarding the share of investments into HS, OM, and PD. The maturity grid is used for gathering the staff's perception regarding DM and UI of each IT service in a hospital (based on semantic differential scales). In order to check for possible confounding, we collected further measures such as the number of registered users per application, application complexity or responsibilities for application support. A pre-test of the instrument was performed by means of an assisted, voluntary assessment with thirteen hospitals. 
In 2009, to extend our outreach, we changed from a third-party assisted assessment, where we used structured interviews for collecting the data of hospitals, to a computerized selfassessment by which selected representatives (e.g. the hospital's chief information officer or a person assuming a similar role in hospitals without this job profile) independently provide us with the necessary data and that included more advanced data handling and visualization algorithms (see Appendix C). Changing the mode of data collection and analysis considerably reduced our workload as we only have to check for inconsistencies or incorrect data entries, which in case of problems are fixed in collaborative discussion with the hospital representative. It also allowed us to concentrate on new activities, like the creation of a community of practice for healthcare IT professionals, for which we organize yearly meetings to foster an open exchange of ideas among the participating hospitals and to promote a culture of learning regarding digitalization efforts. As of 2014, we gathered longitudinal data of thirty-five Swiss public hospitals.

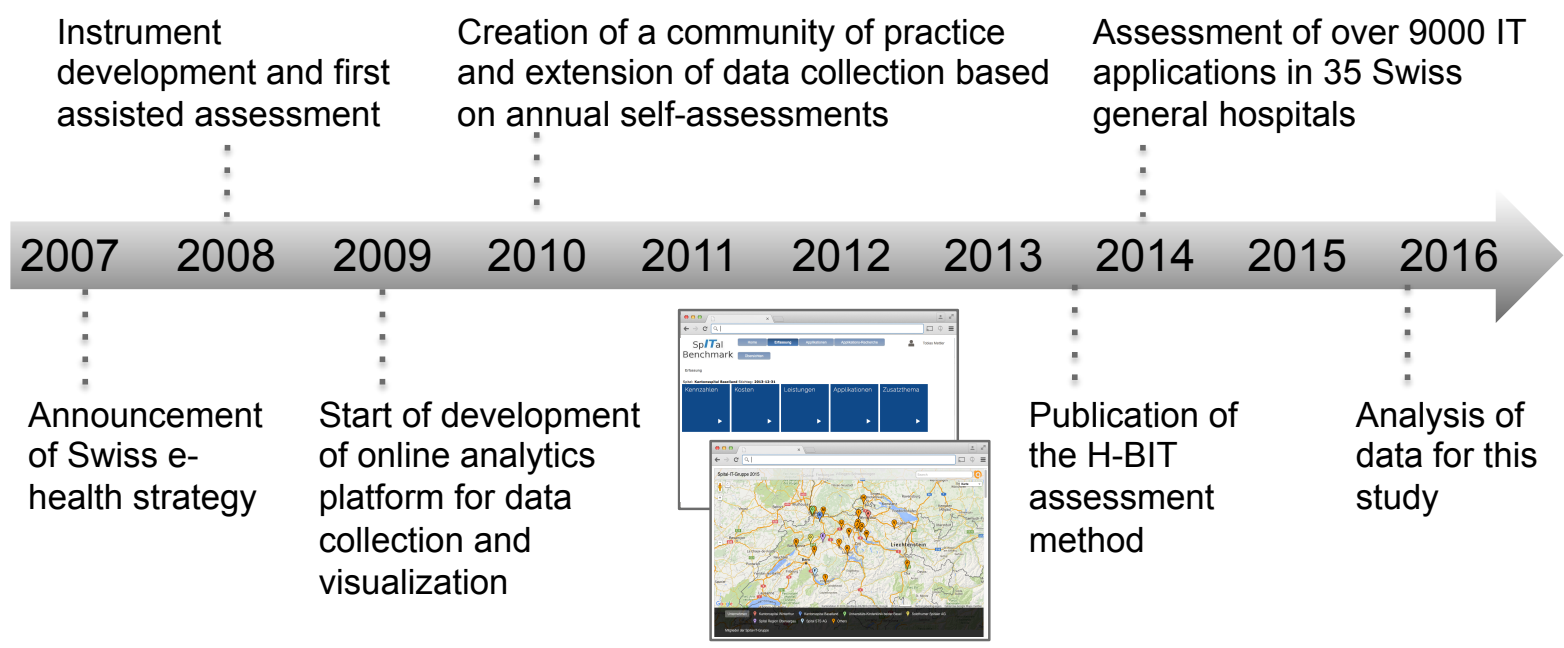

Figure 2. Illustration of data collection and timeline of events.

Descriptive statistics for the longitudinal data set between 2008 and 2014 are shown in Table 2 . Our sample size $(n=35)$ corresponds to around $30 \%$ of the total population or $44 \%$ of public hospitals in Switzerland (Swiss Federal Statistical Office, 2014). Our sample does not include private hospitals. For cross-sectional analyses, we used data from the most recent assessment. 
Table 2. Descriptive statistics of sample $(n=35)$.

\begin{tabular}{lrrrrr}
\hline Item & MEAN & MEDIAN & SD & MIN & MAX \\
\hline Number of cases per year & 112,645 & 51,850 & 145,703 & 4,669 & 583,588 \\
$\quad$ Inpatient cases & 14,803 & 9,739 & 12,918 & 1,306 & 64,048 \\
$\quad$ Outpatient cases & 97,843 & 43,380 & 136,075 & 0 & 543,903 \\
Number of registered users & 1,657 & 789 & 2,100 & 71 & 9,188 \\
Number of IT-applications & 55 & 57 & 23 & 6 & 95 \\
$\quad$ Medical applications & 36 & 37 & 16 & 4 & 63 \\
Administrative applications & 18 & 19 & 9 & 2 & 37 \\
IT personnel at hospital (FTE) & 16.99 & 8.80 & 22.45 & 0.20 & 91.65 \\
Total IT spending per year (in & $6,746,467$ & $4,095,583$ & $7,448,943$ & 954,034 & $38,476,819$ \\
CHF) & & & & & \\
$\quad$ Hardware \& software & $1,995,020$ & $1,313,494$ & $2,963,006$ & 200,943 & $16,015,938$ \\
investments & & & & & \\
$\quad$ Operations \& maintenance & $2,510,803$ & $1,505,599$ & $2,527,690$ & 222,973 & $10,679,650$ \\
services & & & & & \\
$\quad$ IT personnel \& training costs & $2,073,866$ & $1,169,670$ & $2,385,903$ & 507,214 & $11,654,514$ \\
\hline
\end{tabular}

\subsection{Statistical analysis}

In order to test our hypotheses, proposing that certain kinds of investments positively influence digital maturity and ultimately lead to higher usage intensity in hospitals, we performed a statistical path analysis using STATA ${ }^{\circledR}$ version 13. Additional exploratory data visualization techniques were used to better understand the evolutionary aspects in the collected data.

Path analysis (PA) is a special case of structured equation modeling (SEM), containing only observed variables. A major advantage of using PA compared with other statistical techniques is the fact that it permits examination of complex associations including various types of data (e.g., categorical, dimensional, censored, count variables) and can be used with relatively small sample sizes (Wolf et al., 2013). However, this flexibility in using PA makes it difficult to develop generalized guidelines so as to quality criteria and sample size requirements (MacCallum et al., 1996). Therefore several authors suggest to use a combined set of goodnessof-fit criteria to assess the quality and power of estimated model (Bagozzi \& Yi, 1988; Hu \& Bentler, 1999). When examining sample sizes, investigators usually prioritize achieving adequate statistical power to observe true relationships in the data. Based on (Bentler \& Chou, 1987), 5 or 10 observations per estimated parameter are sufficient, however, according to 
(MacCallum et al., 1996) the root mean squared error of approximation (RMSEA)—with an acceptable value below 0.05 - is a more precise vehicle for statistical power and the determination of the necessary sample size.

Besides RMSEA, (Hu \& Bentler, 1999) suggest to also consider other fit indices, such as the standardized root mean squared residual (SRMR) or Tucker-Lewis index (TLI) with an acceptable cut-off value below 0.08 and above 0.9 respectively. Best fit for our recursive model was achieved with maximum likelihood estimations. As shown in Table 3, our model complied with all the prior mentioned criteria.

Table 3. Goodness-of-fit of path model.

\begin{tabular}{lccl}
\hline Criterion & Value & Acceptable & Source \\
\hline Root mean squared error of & 0.00 & $<0.05$ & (MacCallum et al., 1996) \\
$\begin{array}{l}\text { approximation (RMSEA) } \\
\text { Standardized root mean squared }\end{array}$ & 0.04 & $<0.08$ & (Hu \& Bentler, 1999) \\
residual (SRMR) & & & \\
Tucker-Lewis index (TLI) & 1.15 & $>0.9$ & (Hu \& Bentler, 1999) \\
\hline
\end{tabular}

\section{RESULTS}

In this section, we describe both explanatory and exploratory findings of our study. Each subsection describes one essential takeaway with respect to the influencing factors and/or evolutionary paths of digital maturity in hospitals. Continuing with the same pragmatist epistemology such as used in the review of the literature (Tavory, 2016), we additionally provide some interpretation of our findings.

\subsection{Takeaway 1: Only investment into hardware and software significantly drives perception about digital maturity}

As discussed before, digital maturity is a relative and subjective concept with several simultaneously existing connotations and meanings. Prior research therefore suggested employing IT-related investments as proxy or possible indicator of digital maturity. The results from our PA thus explain to which extent certain investments in technology and personnel, on 
average, have a positive influence on the perceived digital maturity of a hospital. The mean ratio of hardware and software investments (HS) compared to the total HIT spending per hospital was $0.27(\mathrm{SD}=0.09 ; \min =0.12 ; \max =0.46)$. The mean ratio of operations and maintenance investments $(\mathrm{OM})$ was $0.38(\mathrm{SD}=0.11 ; \min =0.12$; $\max =0.63)$. The main ratio for personnel development $(\mathrm{PD})$ was $0.31(\mathrm{SD}=0.08$; $\min =0.16$; $\max =0.53)$.

The graphical illustration of our PA is shown in Figure 3. Each of our four initially defined hypotheses represents a specific relation or path in our computed model (direct lines in Figure 3). Not all hypotheses were significant (red lines in Figure 3 mark significant relations). We also tested for correlations between the different investment categories (curved lines in Figure 3). Table 4 shows the maximum-likelihood estimates (with default standard errors) of the path coefficients.

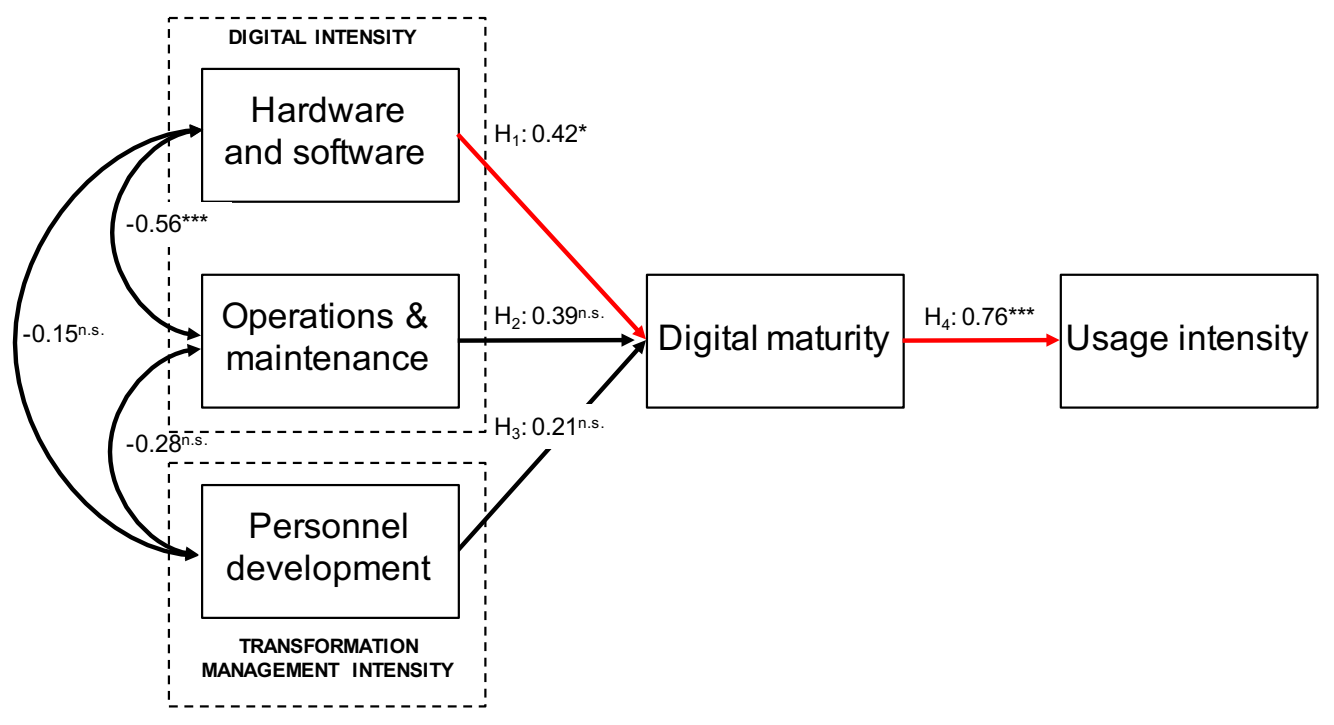

Figure 3. Results of path analysis with significance at * $\mathrm{p}<0.05 ;{ }^{* *} \mathrm{p}<0.01 ;{ }^{* * *} \mathrm{p}<0.001$.

Table 4. Standardized path coefficients, p-values and hypothesis evaluation 


$\begin{array}{llllll}\text { H1: Hardware \& software (HS) } & \rightarrow \text { digital maturity (DM) } & 0.42 & 0.22 & 0.05^{*} & \text { significant } \\ \text { H2: Operations \& maintenance (OM) } & \rightarrow \text { digital maturity (DM) } & 0.39 & 0.230 .09 & \text { not significant } \\ \text { H3: IT personnel development (PD) } & \rightarrow \text { digital maturity (DM) } & 0.21 & 0.190 .29 & \text { not significant } \\ \text { H4: Digital maturity (DM) } & \rightarrow \text { usage intensity (UI) } & 0.76 & 0.08 & 0.00^{* * *} & \text { significant }\end{array}$

Note: Significance at ${ }^{*} \mathrm{p}<0.05 ;{ }^{* *} \mathrm{p}<0.01 ;{ }^{* * *} \mathrm{p}<0.001$.

First, our path analysis revealed that the relationship between personnel development and digital maturity $(\mathrm{H} 3)$ is not indicative, which could lead to the interpretation that transformation management intensity plays a lesser role in shaping the perception about digital maturity. This is somehow counterintuitive, since several prior studies have shown that low IT literacy among health professionals is a major inhibitor of technological advancement in hospitals and we therefore would have expected that better trained and informed personnel is more inclined to judge positively regarding the digital maturity of their hospital. Contrariwise, increased IT literacy respectively clarity about the capabilities and affordances of the hospital's HIT infrastructure could also have led to a negative perception. This particularly happens when health professionals compare the IT-capabilities of their work environment with private use contexts (e.g. poor ease-of-use of clinical e-mail system because of the necessity of encrypted information exchange) or with other industries (e.g. complex billing systems as opposed to rather simple e-commerce systems). Since the relation is not significant, we cannot posit an a-priori relationship between personnel development and digital maturity.

Second, our path analysis also revealed that investments into more professional operations and maintenance services have no significant influence on digital maturity (H2). This means that we could not find evidence that a professionally operated HIT infrastructure (e.g. with higher reliability and availability, increased service levels) necessarily leads to a higher perceived digital maturity of the hospital. Again, this is contradictive to previous studies since most conceptual approaches for measuring and improving digital maturity, particularly the ones based on the well-known capability maturity model (CMM) methodology, act on the assumption that maturity is primarily optimized through process improvement. Our results, however, indicate that enhanced maintenance and operations do not play a significant role. 
This may be related to the "commoditization" of many aspects of IT: in this regard, many under-the-hood operations, such as maintenance, support services or system management, for example, are taken for granted by the users, that do not perceive their actual value. This may also indicate a higher stress on the perceived HIT performance with regard to the quality of service provided rather than the mere functioning.

Third, and most notably, we could show that only investments in new hardware and software have a weak (0.42), but significant positive effect on the perceived digital maturity (H1). This implies that health professionals first and foremost respond to obvious alterations of the HIT infrastructure (e.g. purchasing of new devices, software release changes). As opposed to the extant literature where high digital maturity is predominantly understood as extensive data and process integration in hospitals (second definition in Table 1), we therefore infer from this finding that health professionals in reality comprehend digital maturity rather as transition from paper to electronic methods of working, or as fusion of physical and digital infrastructure components (first and third definition in Table 1), enabling advanced and higher quality services.

Overall, the results from testing these paths (H1-H3) should be taken with caution because the three variables together could only explain about 12 per cent of the variance of digital maturity, which is certainly a limitation of this study. In investigating recursive effects in the different investment categories, we found strong negative correlations between HS and OM investments

(-0.56) and weak negative correlations between HS and PD (-0.15) and between OM and PD (-0.28). However, only correlation effects between HS and OM were significant. This result could be interpreted as a trade-off effect in budget allocation between "running" and "changing" the organization. In this sense, our model suggests that an increase in OM, which does not affect digital maturity, leads to a reduced budget for HS, which indeed has a weak effect on digital maturity.

Although our results could not sufficiently prove the effects leading to digital maturity, we could detect a highly significant and rather strong effect (0.76) between digital maturity and usage intensity (H4), with an explained variance of 58 per cent. This means that the higher the maturity of a HIT application perceived by health professionals, the more likely is its usage 
across different departments and/or user groups in the hospital. This is interesting as our findings imply that together with an increase of digital maturity also a wider usage is achieved, which ultimately should be the goal of any digital initiative in the health system.

\subsection{Takeaway 2: Once digitally mature, not always digitally mature}

We have propagated digital maturity as a relative concept describing to which extent stakeholders perceive that their work environment shows high uptake of digital services and recognize HIT role in providing high quality services. We have, however, not discussed its relativity in terms of temporal changes.

Digital maturity can be considered as a hospital's organizational asset that needs some effort to be maintained and nurtured over time. Today, hospitals have to cope with increased patient and workforce expectations with respect to their HIT infrastructure: think about the rapid advancement of social media, mobile applications, or service robotics-to mention just a few examples. Hence, taking a more dynamic perspective on the data of our online analytics platform, we see in Figure 4 that the hospitals in our sample have evolved quite differently between 2008 and 2014 - either enhancing or worsening their digital maturity and usage intensity. 

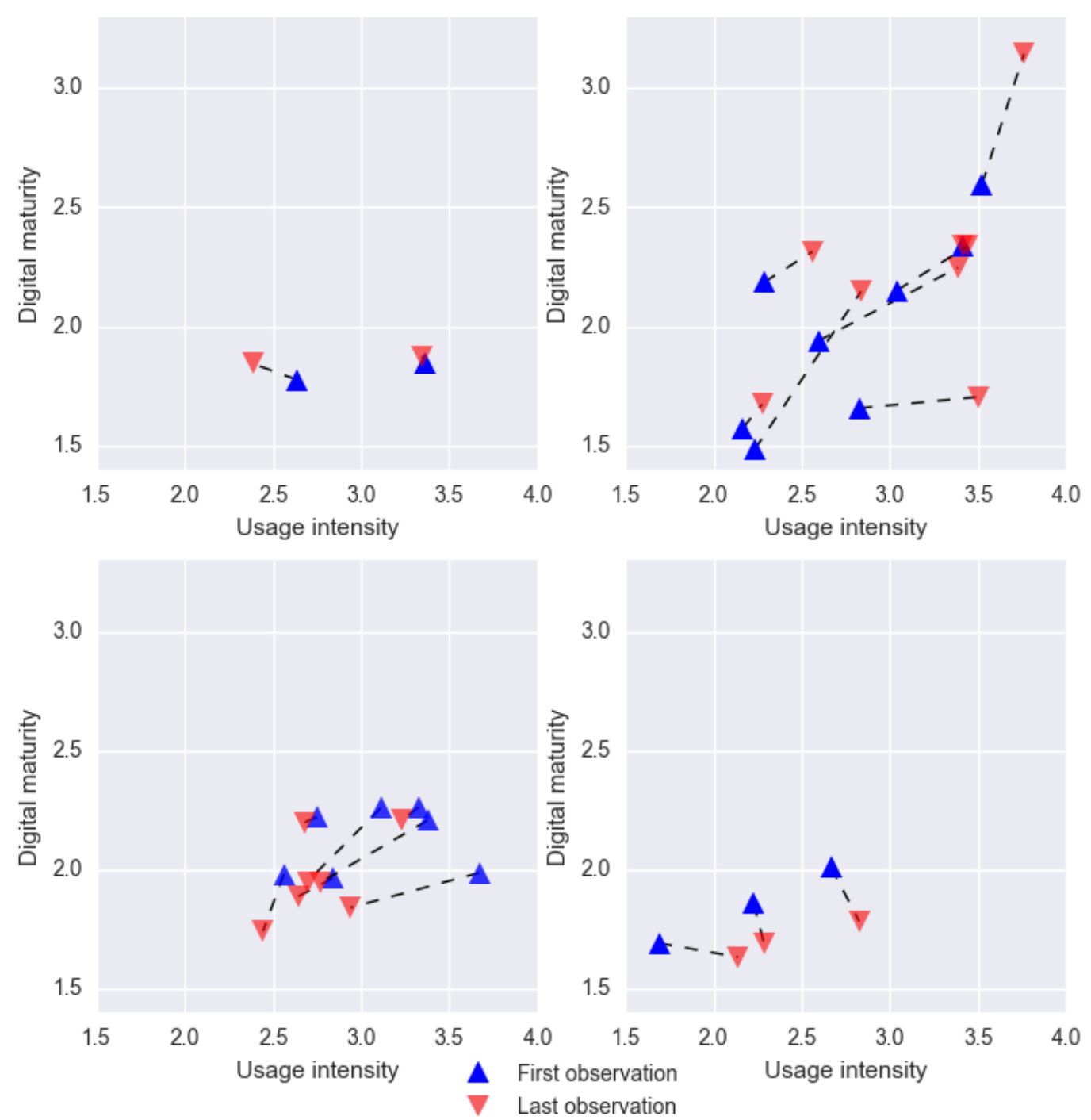

Figure 4. Evolution of digital maturity and usage intensity in selected Swiss hospitals.

Over time, some hospitals in the sample have been able to improve their overall situation with respect to both the dimensions (upper-right quadrant), whereas many others have experienced a substantial deterioration (lower-left quadrant). However, the path connecting the initial and final situations can be quite convoluted, as shown in Figure 5, where the "evolutionary path" of few hospitals is reported in detail. In the case of Hospital 1, the overall situation worsened over time, while Hospital 2 improved both the maturity and the usage intensity. In both cases, the paths show alternating results from year to year. Hospital 3, instead, followed a quite consistent path leading to a substantial improvement of both usage intensity and digital maturity. 

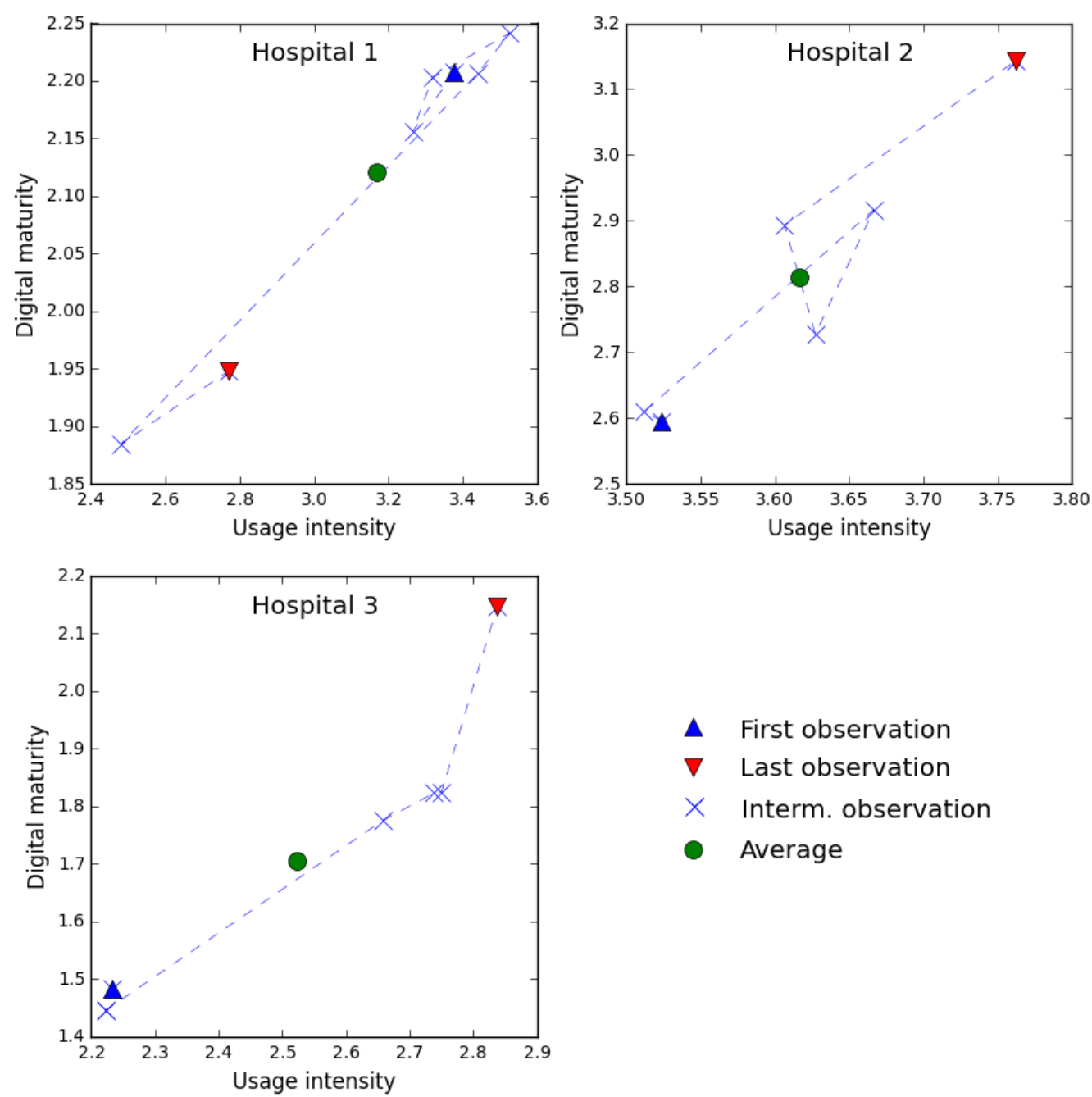

A First observation

$\nabla$ Last observation

$\times$ Interm. observation

- Average

Figure 5. Digital maturity and usage intensity exemplificative evolutionary paths in Swiss hospitals.

Based on what is known in the literature, and because the data on our online analytics platform does not allow for an exact answer concerning the different evolutionary patterns, we posit that this change in the perception concerning the hospital's digital maturity can be attributed to the following reasons:

- Digital maturity decreases because the external business and social environment becomes more advanced and challenging, and the application portfolio no longer fits with the expectations and best practices of the eco-system. For example, like (Gandhi et al., 2018) highlights, it is common to use highly sophisticated technology for medical diagnostics, while less than 20 percent of the hospitals are being capable of performing online payments with their suppliers. This negative perception may especially become apparent 
when end-users exhibit and use a more advanced technological infrastructure in their private life compared to what is available at their workplace.

- Digital maturity changes along with the user base. Today's digital natives are replacing the analog natives retiring workforce (or even the older digital natives), bringing even more pressure on the necessity to innovate the application portfolio of the hospitals. Following (Prensky, 2001), customers and workers "think and process information fundamentally differently from their predecessors." Therefore, new worker generations sometimes enter a working place where the level of innovation is stagnating, thus leading to a different maturity assessment level.

- Digital maturity decreases because users adapt the systems to other usages different from those for which the system was designed (Fadel, 2012). The perceived maturity decreases as a consequence of the difficulties of the system to adapt to mutated exigencies from the customers and the workers as well as the necessity to develop workarounds for being able to work productively (Alter, 2014).

- Eventually, digital maturity may decrease just after the introduction of a new application due to the users' unpreparedness. Moreover, as discusses previously, personnel development initiatives seem not effective in supporting a positive perception of the hospital digital maturity. The fact that particularly seasoned professionals have difficulties in admitting their deficiencies when coping with IT (or asking for help), has been extensively researched in the past and is often perceived as catalyst for resistant behavior or even for the withdrawal of the application (Bhattacherjee \& Hikmet, 2007; MichelVerkerke \& Spil, 2013; Wisdom et al., 2013).

The first three points underline once more how the role of new investments in hardware and software is pivotal in driving up the perceived digital maturity (see the PA results, H1).

\subsection{Takeaway 3: Even comparatively mature hospitals have 'white spots' on their digitalization roadmap}

Lastly, our longitudinal observation also shows that there is great room for improvement-even for comparatively mature hospitals. As shown in Figure 6, white spots (i.e. missing or poorly adopted applications) can be found in practically all of our surveyed hospitals. Overall, 30 out 
of 47 application types considered in this study were present in more than $80 \%$ of the sample, whereas six application types were present in less than $45 \%$ of the sample. One common trait, however, is the extremely low diffusion (i.e. the ratio between the number of hospitals in which the application type is present and the total number of hospitals in the sample) of customer relationship management systems, only adopted in less than $9 \%$ of the sample and with an extremely low average maturity. A similar pattern is followed by patient self-service systems, present in less than $15 \%$ of the sample.

On the other end, no hospital can operate without applications related to clinical reporting, clinical activity recording, medical communication and personnel planning, assuming that recent changes in health policy, such as the introduction of a case-based remuneration scheme in 2012 based on diagnosis-related groups (DRG), have accelerated the digitalization of certain, yet extremely specialized areas of the hospital.

Our data gives us at least some evidence why certain studies come to the conclusion that healthcare is at the lower end of the digital transformation (Gandhi et al., 2018):

- The focus of digitalization efforts is mainly internal (i.e. towards the optimization of the internal work environment and directed towards the needs of health professionals) and is often advanced by departmental initiatives and/or local problem solving in the hospital. The reason for the disinterest in digitalized services with a view to external stakeholders (e.g. patients, referring family doctors and specialists, suppliers, insurers) could be diverse, such as a predominant departmental allocation of IT budgets (hence low incentives for cross-departmental collaboration), missing responsibilities concerning intra- and interorganizational processes, or simply unawareness of the vast possibilities to improve the digital outside appearance of the hospital.

- Digitalization is conducted in a reactive way (i.e. after health policy changes) or seen as one-time duty. As discussed previously, digital maturity is an evolutionary concept that requires a constant and active monitoring and adaptation of the HIT infrastructure. What seemed to be impossible, disproportionate, or unnecessary some years ago might be common practice in most other industries of today. Accordingly, hospitals not only need an inside and outside perspective, but additionally also a cross-industry perspective on digitalization trends. 


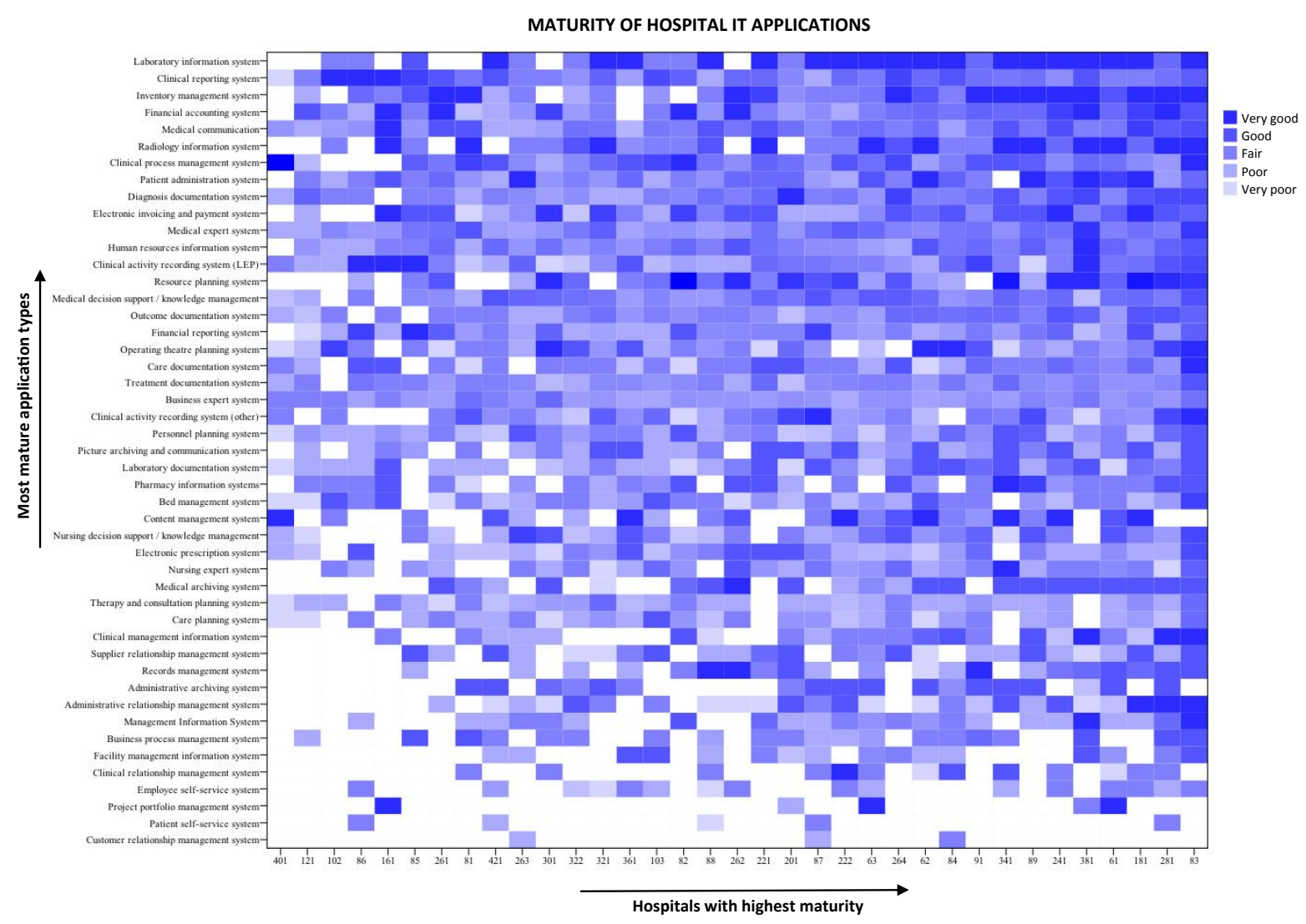

Figure 6. Heat map illustrating the perceived digital maturity of different HIT applications and 'white spots' in selected Swiss hospitals.

\section{LIMITATIONS}

When interpreting the findings presented in this study, the reader should be aware of the following limitations: First, this study purposefully understood HIT as medical and administrative IT-applications used within hospitals. As mentioned previously, the domain of use and primary use intention of HIT may be understood differently and go beyond the surrounding of a hospital.

Second, the concept of 'digital maturity' as operationalized in this study relies on the perceived estimates and personal appraisal of health professionals. Albeit we attenuate this fact by also taking quantitative financial data into account, our results may additionally be influenced by contextual factors emanating from the Swiss healthcare system (e.g. financial endowment of hospitals, remuneration policy and so on), which makes it difficult to provide a generalization for an international setting. Third, our sample consisted of thirty-five public hospitals, 
accounting for $30 \%$ of the total population, but did not cover the situation in private institutions, which could differ in many ways.

\section{CONCLUSIONS}

While most studies either center on explaining the design of new maturity models that capture certain aspects of digital maturity or on generalized statements to describe the status of 'digital healthcare', the purpose of this study is to provide evidence regarding the evolutionary paths and drivers of digital maturity. Through the analysis of an extensive dataset regarding a population representing $44 \%$ of public hospitals in Switzerland and spanning over several years, we demonstrate that digital maturity is a relative and subjective construct that either improves or worsens over time, is bound to perceptions of health professionals, and seldom reaches a final stage. We also found that investments into hardware and software mainly positively influence digital maturity, while investments into maintenance and operations and personnel development do not.

The presented evidence suggests the possibility to investigate further the subject under different perspectives. In this respect, the weak influence of IT personnel development initiatives on the digital maturity perception may indicate a gap between what the users expect and what they should be legitimate to expect; indeed, people frequently do not differentiate between their private environment (where "everything" works) and the corporate setting where things seem to be more complicated, obsolete, or not working at all. Thus, hospital management together with HIT responsible should support the users in shaping their expectations, not only providing technical development initiatives, but also communicating the legitimate roles and purpose of HIT components. There is difficulty in translating requirements, needs and wants among specialties, stakeholders, clinicians, and implementers, sometimes to the point of a seeming "culture clash" (Kaplan \& Harris-Salamone, 2009.)Further, the change processes required for achieving the desired informatics and organizational outcome goals are demanding and complicated, especially in extremely complex organizations that operate on a $7 \times 24$ basis (Lorenzi et al., 1998).

Although evident initiatives such as investments in new hardware and software positively influence the perception of digital maturity by signaling an advancement of HIT towards the 
latest IT innovations, a more profound understanding of the digital maturity as the extent to which digital technologies are used as enablers to deliver a high-quality health service would allow focusing on the outcomes rather than on the infrastructure and equipment.

From the IT department perspective, digital maturity as discussed in this paper allows creating awareness about the volatility of users' expectations, which are often influenced by external events and users own experience. In this respect, managing the expectations could also help in improving the overall performance and usage of HIT. Indeed, even if excellent processes are running, false or inflated expectations can jeopardize the users experience, leading them to a negative overall perception of digital maturity.

In conclusion, although subjective and relative, digital maturity is an organization's asset requiring resources and focus. When carefully managed, it represents a way for engaging with different actors and for discussing improvement initiatives beyond single technologies or projects.

\section{FUNDING}

This research received no specific grant from any funding agency in the public, commercial, or not-for-profit sectors.

\section{COMPETING INTERESTS}

The authors have no competing interests to declare.

\section{REFERENCES}

Abraham, C., Nishihara, E. \& Akiyama, M. (2011) Transforming healthcare with information technology in Japan: A review of policy, people, and progress. International Journal of Medical Informatics, 80(3), 157-170.

Agarwal, R., Gao, G., DesRoches, C. \& Jha, A. K. (2010) Research commentary-The digital transformation of healthcare: Current status and the road ahead. Information Systems Research, 21(4), 796-809. 
Agarwal, R. \& Prasad, J. (1998) The antecedents and consequents of user perceptions in information technology adoption. Decision Support Systems, 22(1), 15-29.

Alter, S. (2014) Theory of workarounds. Communications of the Association for Information Systems, 34(1), 1041-1066.

American Hospital Association (2018) AHA annual survey IT database [Online]. Available: http://www.ahadataviewer.com/about/it-database/ [Accessed February 15, 2018].

Bagozzi, R. P. \& Yi, Y. (1988) On the evaluation of structural equation models. Academy of Marketing Science, 16(1), 74-94.

Baldwin, G. (2009) A digital hospital at work. Health Data Management, 17(8), 43-45.

Bates, D. W. \& Gawande, A. A. (2003) Improving safety with information technology. New England Journal of Medicine, 348(25), 2526-2534.

Bentler, P. M. \& Chou, C. H. (1987) Practical issues in structural modeling. Sociological Methods E Research, 16(1), 78-117.

Bhattacherjee, A. \& Hikmet, N. (2007) Physicians' resistance toward healthcare information technology: A theoretical model and empirical test. European Journal of Information Systems, 16(6), 725-737.

Brynjolfsson, E. (1993) The productivity paradox of information technology. Communications of the ACM, 36(12), 66-77.

Burbridge, B. \& Bell, C. (2004) The digital readiness of imaging facilities in Saskatchewan. Canadian Association of Radiologists Journal-Journal De L Association Canadienne Des Radiologistes, 55(5), 311-314.

Chang, Z. J., Mei, S., Gu, Z., Gu, J. Q., Xia, L. X., Liang, S. \& Lin, J. R. (2003) Realization of integration and working procedure on digital hospital infon-nation system. Computer Standards \& Interfaces, 25(5), 529-537.

Chaudhry, B., Wang, J., Wu, S., Maglione, M., Mojica, W., Roth, E., Morton, S. C. \& Shekelle, P. G. (2006) Systematic review: Impact of health information technology on quality, efficiency, and costs of medical care. Annals of Internal Medicine, 144(10), 742-752.

Chiasson, M. W. \& Davidson, E. (2004) Pushing the contextual envelope: Developing and diffusing is theory for health information systems research. Information and Organization, 14(3), 155-188. 
Coile, R. C., Jr. (2003) Managing the digital hospital. Physician Executive, 29(3), 48-51.

Cutler, D., Wikler, E. \& Basch, P. (2012) Reducing administrative costs and improving the health care system. New England Journal of Medicine, 367(20).

Deidda, M., Lupiáñez-Villanueva, F. \& Maghiros, I. (2013) European hospital survey: Benchmarking deployment of e-health services. Seville: Institute for Prospective Technological Studies of the European Commission.

Devaraj, S. \& Kohli, R. (2000) Information technology payoff in the health-care industry: A longitudinal study. Journal of Management Information Systems, 16(4), 41-67.

Eastaugh, S. R. (2012) Health information technology impact on productivity. Journal of Health Care Finance, 39(2), 64-81.

Fadel, K. J. (2012) User adaptation and infusion of information systems. Journal of Computer Information Systems, 52(3), 1-10.

Flott, K., Callahan, R., Darzi, A. \& Mayer, E. (2016) A patient-centered framework for evaluating digital maturity of health services: A systematic review. Journal of Medical Internet Research, 18(4), e75.

Gandhi, P., Khanna, S. \& Ramaswamy, S. (2018) Which industries are the most digital (and why)? [Online]. Available: https://hbr.org/2016/04/a-chart-that-shows-which-industriesare-the-most-digital-and-why [Accessed February 15, 2018].

Gao, X., Muller, H. \& Deserno, T. M. (2011) Integration of medical images into the digital hospital. The Open Medical Informatics Journal, 5(Suppl 1), 17-8.

Gastaldi, L., Pietrosi, A., Lessanibahri, S., Paparella, M., Scaccianoce, A., Provenzale, G., Corso, M. \& Gridelli, B. (2018) Measuring the maturity of business intelligence in healthcare: Supporting the development of a roadmap toward precision medicine within ismett hospital. Technological Forecasting and Social Change, 128, 84-103.

Habal, M. B. (2004) The digital hospital and the digital chart. The Journal Of Craniofacial Surgery, 15(4), 539-540.

Hebert, M. A. (1998) Impact of it on health care professionals: Changes in work and the productivity paradox. Health Services Management Research, 11(2), 69-79.

Hewlett-Packard Company (2006) The time has (finally) come for the digital hospital. Healthcare Quaterly, 10, 40-42. 
Hillestad, R., Bigelow, J., Bower, A., Girosi, F., Meili, R., Scoville, R. \& Taylor, R. (2005) Can electronic medical record systems transform health care? Potential health benefits, savings, and costs. Health Affairs, 24(5), 1103-1117.

HIMSS Foundation (2018) Dorenfest complete integrated healthcare delivery systems plus database (himss) [Online]. Available: http://apps.himss.org/foundation/histdata.asp?/foundation/histdata.asp/ [Accessed February 15, 2018].

Holland, M., Piai, S. \& Dunbrack, L. A. (2008) Healthcare it maturity model: Western european hospitals - the leading countries Framingham, MA: IDC Health Insights.

HPlus (2018). Available:

http://www.hplus.ch/de/dienstleistungen/betriebswirtschaft/rechnungswesen_spital/rek oler handbuch/ [Accessed February 15, 2018].

Hruby, W., Mosser, H., Urban, M. \& Ruger, W. (1992) The Vienna SMZO-PACS-project - The totally digital hospital. European Journal of Radiology, 16(1), 66-68.

Hruby, W., Pärtan, G., Mosser, H., Krampla, W. \& Malcher, J. (1996) The digital hospital information technology in radiology. RBM-News, 18(5), 153-158.

Hu, L. \& Bentler, P. M. (1999) Cutoff criteria for fit indexes in covariance structure analysis: Conventional criteria versus new alternatives. Structural Equation Modeling, 6(1), 1-55.

IDC (2015) Annual IT spending by Western European healthcare providers to reach $\$ 14.6$ billion by 2018. London: IDC.

Jahn, F. \& Winter, A. (2011) A KPI framework for process-based benchmarking of hospital information systems. Studies in Health Technology and Informatics, 169, 542-546.

Jeong, C.-W., Lee, S. G., Lee, J., Yoon, K.-H. \& Joo, S. C. (2015) Construction of dynamic medical information system for digital hospital environments. Wireless Personal Communications, 1-16.

Jones, S. S., Heaton, P. S., Rudin, R. S. \& Schneider, E. C. (2012) Unraveling the IT productivity paradox — Lessons for health care. New England Journal of Medicine, 366(24), 22432245.

Kaelber, D. C. \& Bates, D. W. (2007) Health information exchange and patient safety. Journal of Biomedical Informatics, 40(6), S40-S45. 
Kane, G. C., Palmer, D., Nguyen Phillips, A., Kiron, D. \& Buckley, N. (2017) Achieving digital maturity: Adapting your company to a changing world. Boston: MIT Sloan Management Review and Deloitte University Press.

Kaplan, B. \& Harris-Salamone, K. D. (2009) Health IT success and failure: Recommendations from literature and an AMIA workshop. Journal of American Medical Informatics Association, 16(3), 291-299.

King, L. A., Fisher, J. E., Jacquin, L. \& Zeltwanger, P. E. (2003) The digital hospital: Opportunities and challenges. Journal of healthcare information management : JHIM, 17(1), 37-45.

Kohli, R., Devaraj, S. \& Ow, T. T. (2012) Does information technology investment influence a firm's market value? A case of non-publicly traded healthcare firms. MIS Quarterly, 36(4), 1145-1163.

Kohli, R. \& Grover, V. (2008) Business value of IT: An essay on expanding research directions to keep up with the times. Journal of the Association for Information Systems, 9(1), 2339.

Kramer, S. (2006) Creating a digital hospital. Tanya Townsend of Saint Clare's hospital has worked hard to go digital. Healthcare Informatics: The Business Magazine for Information and Communication Systems, 23(9), 48.

Lacanna, G. (2013) The role of information and communication technology in planning the digital hospital. World Hospitals and Health Services: The Official Journal of the International Hospital Federation, 49(3), 4-6.

Lapointe, L., Mignerat, M. \& Vedel, I. (2011) The IT productivity paradox in health: A stakeholder's perspective. International Journal of Medical Informatics, 80(2), 102-115.

Li, X.-G. \& Gao, W.-M. (2014) Study on the path of comprehensive reform and development of the people's hospital of shimian county. Annals of Translational Medicine, 2(4), 35-35.

Liebe, J. D. \& Hübner, U. (2013) Developing and trialling an independent, scalable and repeatable it-benchmarking procedure for healthcare organisations. Methods of Information in Medicine, 52(4), 360-369. 
Lorenzi, N. M., Riley, R. T., Blyth, A. J. C., Southon, G. \& Dixon, B. J. (1998) People and organizational aspects of medical informatics. Studies in Health Technology and Informatics, 52, 1197-1200.

Lu, X., Duan, H., Li, H., Zhao, C. \& An, J. (2005) The architecture of enterprise hospital information system. In: Proceedings of the Annual International Conference of the IEEE Engineering in Medicine and Biology Society, Shanghai, China, 6957-60.

Luxton, D. D., McCann, R. A., Bush, N. E., Mishkind, M. C. \& Reger, G. M. (2011) Mhealth for mental health: Integrating smartphone technology in behavioral healthcare. Professional Psychology: Research and Practice, 42(6), 505-512.

MacCallum, R. C., Browne, M. W. \& Sugawara, H. M. (1996) Power analysis and determination of sample size for covariance structure modeling. Psychological Methods, 1(2), 130-149.

Meade, B., Buckley, D. \& Boland, M. (2009) What factors affect the use of electronic patient records by irish gps? International Journal of Medical Informatics, 78(8), 551-558.

Mettler, T. (2011) Maturity assessment models: A design science research approach. International Journal of Society Systems Science, 3(1/2), 81-98.

Mettler, T. (2016) Anticipating mismatches of hit investments: Developing a viability-fit model for e-health services. International Journal of Medical Informatics, 85(1), 104-115.

Mettler, T. \& Raptis, D. A. (2012) What constitutes the field of health information systems? Fostering a systematic framework and research agenda. Health Informatics Journal, $18(2), 147-156$.

Meyer, R. \& Degoulet, P. (2010) Choosing the right amount of healthcare information technologies investments. International Journal of Medical Informatics, 79(4), 225-231.

Michel-Verkerke, M. B. \& Spil, T. A. M. (2013) The use IT-adoption-model to predict and evaluate adoption of information and communication technology in healthcare. Methods of Information in Medicine, 52(6), 475-483.

Miller, R. H., West, C., Martin Brown, T., Sim, I. \& Ganchoff, C. (2005) The value of electronic health records in solo or small group practices. Health Affairs, 24(5), 1127-1137.

Mindel, V. \& Mathiassen, L. (2015) Contextualist inquiry into IT-enabled hospital revenue cycle management: Bridging research and practice. Journal of the Association for Information Systems, 16(12), 1016-1057. 
Mockler, R. \& Dologite, D. (2006) Creating the digital hospital. A number of hospitals are taking steps down the road to automation. Healthcare Informatics: The Business Magazine for Information and Communication Systems, 23(5), 47-50.

Mullaney, T. J. \& Weintraub, A. (2005) The digital hospital - how info tech saves lives and money at one medical center. Is this the future of health care? Business Week, (3926), 77-84.

Murphy, J., Stramer, K., Clamp, S., Grubb, P., Gosland, J. \& Davis, S. (2004) Health informatics education for clinicians and managers-What's holding up progress? International Journal of Medical Informatics, 73(2), 205-213.

National Health Service (2018) Digital maturity assessment [Online]. Available: https://www.england.nhs.uk/digitaltechnology/info-revolution/maturity-index/ [Accessed February 15, 2018].

Otieno, G. O., Hinako, T., Motohiro, A., Daisuke, K. \& Keiko, N. (2008) Measuring effectiveness of electronic medical records systems: Towards building a composite index for benchmarking hospitals. International Journal of Medical Informatics, 77(10), 657-669.

Pagliari, C., Sloan, D., Gregor, P., Sullivan, F., Detmer, D., J.P., K., Oortwijn, W. \& MacGillivray, S. (2005) What is ehealth (4): A scoping exercise to map the field. Journal of Medical Internet Research, 7(1), e9.

Pavlopoulos, S. A. \& Delopoulos, A. N. (1999) Designing and implementing the transition to a fully digital hospital. IEEE Transactions on Information Technology in Biomedicine, 3(1), 6-19.

Peng, D., Liang, M. W., Nan, R. R., Ye, S. H., Yuan, M. F. \& Ishida, T. (2000) Digital city shanghai: Towards integrated information \& service environment. In: Digital cities: Technologies, experiences, and future perspectives, Ishida, T. \& Isbister, K. (eds.), pp. 125-139.

Peng, G., Dey, D. \& Lahiri, A. (2014) Healthcare IT adoption: An analysis of knowledge transfer in socioeconomic networks. Journal of Management Information Systems, 31(3), 7-34. 
Pierre, M. C. (2004) New technology, old issues: The all-digital hospital and medical information privacy. Rutgers Law Review, 56(2), 541-572.

Prensky, M. (2001) Digital natives, digital immigrants. On the Horizon, 9(5), 1-6.

Quintegra (2008) Electronic healthcare maturity model [Online]. Available:

http://www.quintegrasolutions.com/eHMM White Paper.pdf [Accessed February 15, 2018].

Ricke, J. \& Bartelink, H. (2000) Telemedicine and its impact on cancer management. European Journal of Cancer, 36(7), 826-833.

Rollins, G. (2002) The digital hospital: Looking before you leap. Healthcare Executive, 17(5), $24-7$.

Sabherwal, R. \& Jeyaraj, A. (2015) Information technology impacts on firm performance: An extension of Kohli and Devaraj (2003). MIS Quarterly, 39(4), 809-836.

Salzberg, C. A., Jang, Y., Rozenblum, R., Zimlichman, E., Tamblyn, R. \& Bates, D. W. (2012) Policy initiatives for health information technology: A qualitative study of U.S. Expectations and Canada's experience. International Journal of Medical Informatics, 81(10), 713-722.

Samoocha, D., Bruinvels, D. J., Elbers, N. A., Anema, J. R. \& van der Beek, A. J. (2010) Effectiveness of web-based interventions on patient empowerment: A systematic review and meta-analysis. Journal of Medical Internet Research, 12(2), e23.

Sarkar, I. N., Butte, A. J., Lussier, Y. A., Tarczy-Hornoch, P. \& Ohno-Machado, L. (2011) Translational bioinformatics: Linking knowledge across biological and clinical realms. Journal of the American Medical Informatics Association, 18(4), 354-357.

Simpson, J. A. \& Weiner, E. S. C. (1989) The Oxford English Dictionary (2 ed.). Oxford, UK, Oxford University Press.

Swiss Federal Statistical Office (2014) Hospital statistics. Neuchâtel, Switzerland: Swiss Federal Statistical Office.

Tavory, I. (2016) The pragmatist wave of theory construction. The British Journal of Sociology, $67(1), 50-56$.

Thatcher, M. E. \& Pingry, D. E. (2007) Modeling the it value paradox. Communications of the $A C M, 50(8), 41-45$. 
Thouin, M. F., Hoffman, J. J. \& Ford, E. W. (2008) The effect of information technology investment on firm-level performance in the health care industry. Health Care Management Review, 33(1), 60-68.

United States Congress (2009) American recovery and reinvestment act of 2009: Public law 111-5. 2009. Washington (DC).

van Dyk, L. \& Schutte, C. S. L. (2013) The telemedicine service maturity model: A framework for the measurement and improvement of telemedicine services. In: Telemedicine, Madhavan, R. \& Khalid, S. (eds.). InTech, Rijeka, Crotia.

Wang, Y., Kung, L. \& Byrd, T. A. (2018) Big data analytics: Understanding its capabilities and potential benefits for healthcare organizations. Technological Forecasting and Social Change, 126, 3-13.

Waring, T. S. (2015) Information management and technology strategy development in the UK's acute hospital sector: A maturity model perspective. Public Money E Management, 35(4), 281-288.

Weiss, G. (2002) Welcome to the (almost) digital hospital. IEEE Spectrum, 39(3), 44-49.

Westerman, G., Tannou, M., Bonnet, D., Ferraris, P. \& McAfee, A. (2012) The digital advantage: How digital leaders outperform their peers in every industry. Boston, MIT Sloan and Capgemini Consulting.

Williams, C., Asi, Y., Raffenaud, A., Bagwell, M. \& Zeini, I. (2017) The effect of information technology on hospital performance. Health Care Management Science, 11(5), 1.

Wisdom, J. P., Chor, K. H. B., Hoagwood, K. E. \& Horwitz, S. M. (2013) Innovation adoption: A review of theories and constructs. Administration and Policy in Mental Health and Mental Health Services Research, 41(4), 480-502.

Wolf, E. J., Harrington, K. M., Clark, S. L. \& Miller, M. W. (2013) Sample size requirements for structural equation models: An evaluation of power, bias, and solution propriety. Educational and psychological measurement, 76(6), 913-934.

Yoo, S., Kim, S., Lee, K.-H., Jeong, C. W., Youn, S. W., Park, K. U., Moon, S. Y. \& Hwang, H. (2014) Electronically implemented clinical indicators based on a data warehouse in a tertiary hospital: Its clinical benefit and effectiveness. International Journal of Medical Informatics, 83(7), 507-516. 
Yoo, S., Lee, K. H., Lee, H. J., Ha, K., Lim, C., Chin, H. J., Yun, J., Cho, E.-Y., Chung, E., Baek, R.-M., Chung, C. Y., Wee, W. R., Lee, C. H., Lee, H.-S., Byeon, N.-S. \& Hwang, H. (2012) Seoul National University Bundang hospital's electronic system for total care. Healthcare Informatics Research, 18(2), 145-52. 
Appendix A - Literature review on digital maturity / digital hospitals

\begin{tabular}{|c|c|c|c|c|c|c|}
\hline Ref. & Year & PubMed & ISI & Scopus & Type & Digitalization as metaphor for... \\
\hline $\begin{array}{l}\text { (Hruby et al., } \\
1992)\end{array}$ & 1992 & Yes & Yes & Yes & CR & $\begin{array}{l}\ldots \text { the transition from paper to electronic methods } \\
\text { of working }\end{array}$ \\
\hline $\begin{array}{l}\text { (Hruby et al., } \\
\text { 1996) }\end{array}$ & 1996 & No & No & Yes & $\mathrm{CR}$ & $\begin{array}{l}\ldots \text { the transition from paper to electronic methods } \\
\text { of working }\end{array}$ \\
\hline $\begin{array}{l}\text { (Pavlopoulos \& } \\
\text { Delopoulos, 1999) }\end{array}$ & 1999 & Yes & Yes & Yes & RA & $\begin{array}{l}\text {... integrating the existing heterogeneous HIT } \\
\text { landscape }\end{array}$ \\
\hline $\begin{array}{l}\text { (Ricke \& } \\
\text { Bartelink, 2000) }\end{array}$ & 2000 & Yes & No & No & PR & $\begin{array}{l}\ldots \text { integrating the existing heterogeneous HIT } \\
\text { landscape }\end{array}$ \\
\hline (Peng et al., 2000) & 2000 & No & Yes & No & CR & $\begin{array}{l}\text {... integrating the existing heterogeneous HIT } \\
\text { landscape }\end{array}$ \\
\hline (Rollins, 2002) & 2002 & Yes & Yes & Yes & $\mathrm{CR}$ & $\ldots$ achieving a sense of digital patient experience \\
\hline (Weiss, 2002) & 2002 & No & Yes & Yes & $\mathrm{CR}$ & $\begin{array}{l}\text {... integrating the existing heterogeneous HIT } \\
\text { landscape }\end{array}$ \\
\hline (King et al., 2003) & 2003 & Yes & Yes & Yes & PR & $\begin{array}{l}\text {... integrating the existing heterogeneous HIT } \\
\text { landscape }\end{array}$ \\
\hline $\begin{array}{l}\text { (Chang et al., } \\
\text { 2003) }\end{array}$ & 2003 & No & Yes & Yes & RA & $\begin{array}{l}\text {... integrating the existing heterogeneous HIT } \\
\text { landscape }\end{array}$ \\
\hline (Coile, 2003) & 2003 & Yes & Yes & Yes & $\mathrm{PR}$ & ... networked and smart hospital infrastructure \\
\hline (Pierre, 2004) & 2004 & No & Yes & Yes & RA & $\ldots$ achieving a sense of digital patient experience \\
\hline $\begin{array}{l}\text { (Burbridge \& Bell, } \\
\text { 2004) }\end{array}$ & 2004 & Yes & Yes & No & $\mathrm{CR}$ & $\begin{array}{l}\text {... the transition from paper to electronic methods } \\
\text { of working }\end{array}$ \\
\hline (Habal, 2004) & 2004 & Yes & No & Yes & $\mathrm{PR}$ & $\begin{array}{l}\ldots \text { the transition from paper to electronic methods } \\
\text { of working }\end{array}$ \\
\hline (Lu et al., 2005) & 2005 & Yes & Yes & No & RA & $\begin{array}{l}\text {... integrating the existing heterogeneous HIT } \\
\text { landscape }\end{array}$ \\
\hline $\begin{array}{l}\text { (Mullaney \& } \\
\text { Weintraub, 2005) }\end{array}$ & 2005 & No & Yes & No & CR & ... networked and smart hospital infrastructure \\
\hline $\begin{array}{l}\text { (Mockler \& } \\
\text { Dologite, 2006) }\end{array}$ & 2006 & Yes & Yes & Yes & $\mathrm{CR}$ & ... achieving a sense of digital patient experience \\
\hline $\begin{array}{l}\text { (Hewlett-Packard } \\
\text { Company, 2006) }\end{array}$ & 2006 & Yes & Yes & Yes & CR & $\begin{array}{l}\ldots \text { the transition from paper to electronic methods } \\
\text { of working }\end{array}$ \\
\hline (Kramer, 2006) & 2006 & Yes & Yes & Yes & $\mathrm{CR}$ & $\begin{array}{l}\text {... the transition from paper to electronic methods } \\
\text { of working }\end{array}$ \\
\hline (Baldwin, 2009) & 2009 & Yes & Yes & Yes & $\mathrm{CR}$ & $\begin{array}{l}\ldots \text { the transition from paper to electronic methods } \\
\text { of working }\end{array}$ \\
\hline (Gao et al., 2011) & 2011 & Yes & Yes & No & ED & $\begin{array}{l}\ldots \text { integrating the existing heterogeneous HIT } \\
\text { landscape }\end{array}$ \\
\hline (Yoo et al., 2012) & 2012 & Yes & Yes & No & $\mathrm{R}$ & ... networked and smart hospital infrastructure \\
\hline (Lacanna, 2013) & 2013 & Yes & Yes & Yes & $\mathrm{CR}$ & $\ldots$ achieving a sense of digital patient experience \\
\hline (Li \& Gao, 2014) & 2014 & Yes & Yes & No & CR & $\begin{array}{l}\text {... integrating the existing heterogeneous HIT } \\
\text { landscape }\end{array}$ \\
\hline (Yoo et al., 2014) & 2014 & Yes & Yes & No & RA & $\begin{array}{l}\text {... integrating the existing heterogeneous HIT } \\
\text { landscape }\end{array}$ \\
\hline (Jeong et al., 2015) & 2015 & No & No & Yes & RA & $\begin{array}{l}\text {... integrating the existing heterogeneous HIT } \\
\text { landscape }\end{array}$ \\
\hline
\end{tabular}




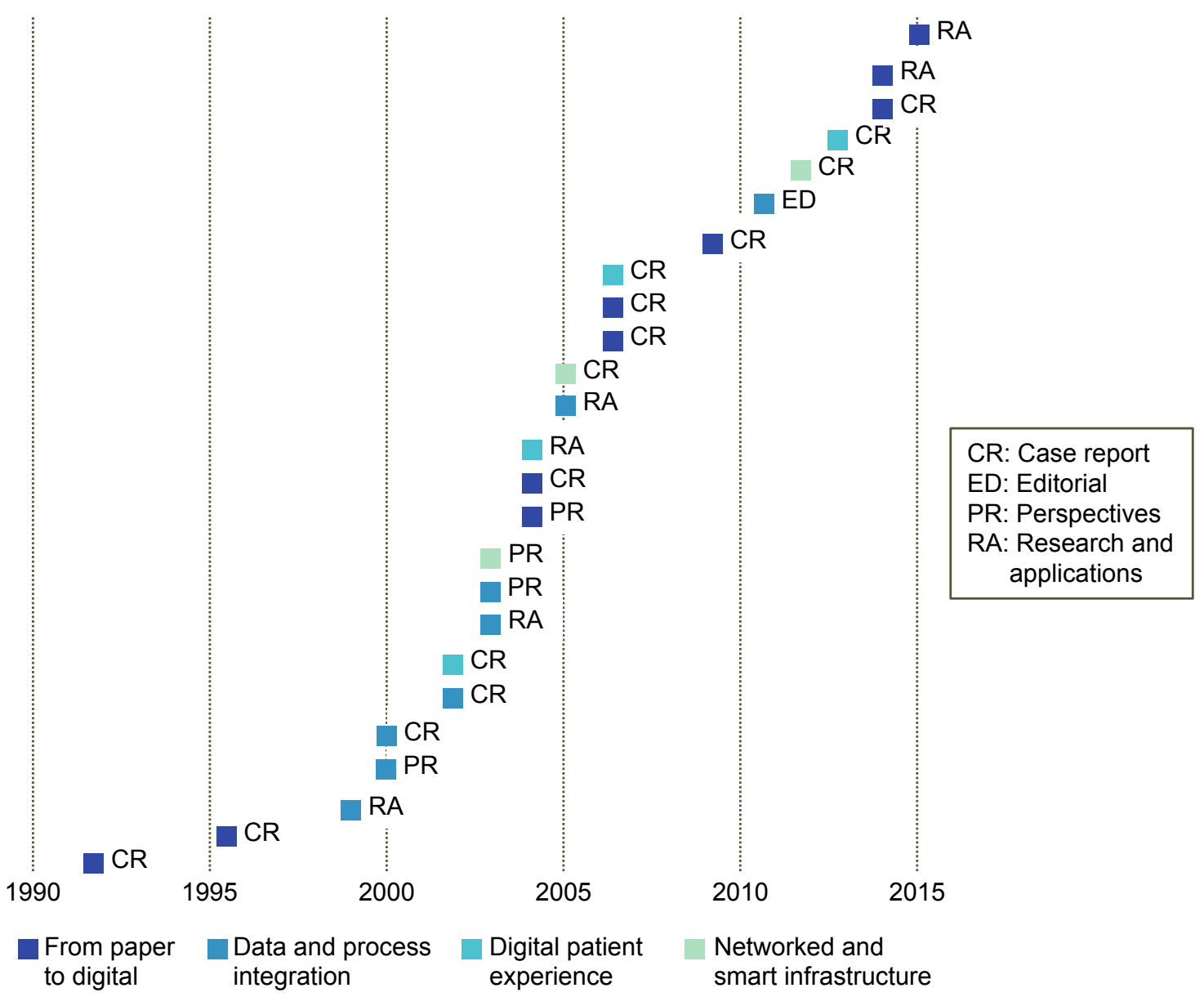

Figure A1. Evolution of conceptual understanding related to the term "digital hospital". 
Appendix B - Benchmarks and maturity models for hospital IT assessments

\begin{tabular}{|c|c|c|c|}
\hline Name & Description & Coverage & Ref. \\
\hline $\begin{array}{l}\text { Annual Survey IT } \\
\text { Database (AHA) }\end{array}$ & $\begin{array}{l}\text { Benchmark of medical IT applications } \\
\text { and infrastructure installed throughout } \\
\text { healthcare organizations } \\
\text { o Mostly medical IT focus }\end{array}$ & $\begin{array}{l}3,300 \text { hospitals in the } \\
\text { U.S. }\end{array}$ & $\begin{array}{l}\text { (American } \\
\text { Hospital } \\
\text { Associatior } \\
\text { 2018) }\end{array}$ \\
\hline $\begin{array}{l}\text { Digital Maturity Index } \\
\text { (NHS) }\end{array}$ & $\begin{array}{l}\text { o Self-assessment of IT-capabilities } \\
\text { (qualitative), IT capital and revenue } \\
\text { budgets of hospitals (quantitative) } \\
\text { o Both administrative and medical IT } \\
\text { o First assessment January } 2016\end{array}$ & $\begin{array}{l}\text { Not yet available } \\
\text { (restricted to NHS } \\
\text { provider } \\
\text { organizations in the } \\
\text { UK) }\end{array}$ & $\begin{array}{l}\text { (National } \\
\text { Health } \\
\text { Service, } \\
\text { 2018) }\end{array}$ \\
\hline
\end{tabular}

Dorenfest Complete Integrated Healthcare Delivery Systems Plus Database (HIMSS)

Electronic Healthcare Maturity Model (Quintegra)

eHealth Benchmarking (Institute for Prospective Technological Studies of the European

Commission)

Hospital IT Applications Maturity Model (IDC)

Telemedicine Service Maturity Model (U. of Stellenbosch) o Benchmark of administrative and medical IT applications and infrastructure installed throughout healthcare organizations

o Estimations of IT purchase plans, market segmentation, and size statistics

\author{
o Maturity grid for determination of \\ existence of medical IT applications \\ and/or infrastructure (according to \\ predefined list) \\ o Mostly medical IT focus
}
- Benchmark of medical IT applications and infrastructure installed throughout healthcare organizations o Mostly medical IT focus
o Maturity grid for determination of existence of medical IT applications (according to predefined list) o Mostly medical IT focus
o Third-party assisted assessment of IT- capabilities and service processes o Mostly medical IT focus

5,400 U.S. non-federal (HIMSS hospitals and 36,000 Foundation, affiliated healthcare 2018) organizations

Not available

(Quintegra, 2008)

Not available (restricted to hospitals in EU member states)

(Deidda $e t$ al., 2013)

Not available

(Holland et al., 2008)

Not available (restricted to hospitals in South Africa) (van Dyk \& Schutte, 2013) 
Appendix C - Operationalization of constructs

\begin{tabular}{|c|c|c|}
\hline Construct & Operationalization & Primary source \\
\hline Hardware \& software & Proportion of annual spending for new & Quantitative data: Annual statement of \\
\hline \multirow[t]{2}{*}{ (HS) } & hardware purchases and software & accounts based on the Swiss REKOLE \\
\hline & licenses to total HIT costs of a hospital & standard (HPlus, 2018) \\
\hline Operations \& & Proportion of annual spending for & Quantitative data: Annual statement of \\
\hline maintenance & operations and maintenance of existing & accounts based on the Swiss REKOLE \\
\hline$(\mathrm{OM})$ & services to total HIT costs of a hospital & standard (HPlus, 2018) \\
\hline Personnel & Proportion of annual spending for & Quantitative data: Annual statement of \\
\hline development & technology-related trainings and skill & accounts based on the Swiss REKOLE \\
\hline \multirow[t]{2}{*}{ (PD) } & development of personnel to total HIT & standard (HPlus, 2018) \\
\hline & costs of a hospital & \\
\hline Digital maturity & Ordinal scale $(0-4)$ related to the & Qualitative data: Annual survey of hospital \\
\hline \multirow[t]{3}{*}{ (DM) } & perceived level of sophistication of a HIT & end-users \\
\hline & service (i.e. $0=$ very low maturity to $4=$ & \\
\hline & very high maturity) & \\
\hline Usage intensity & Ordinal scale $(0-4)$ related to the & Qualitative data: Annual survey of hospital \\
\hline \multirow[t]{4}{*}{ (UI) } & perceived pervasiveness of a HIT service & end-users \\
\hline & (i.e. $0=$ localized usage by single & \\
\hline & users $/$ departments to $4=$ broad usage & \\
\hline & throughout the hospital) & \\
\hline
\end{tabular}


Appendix D - Screenshots of online analytics platform

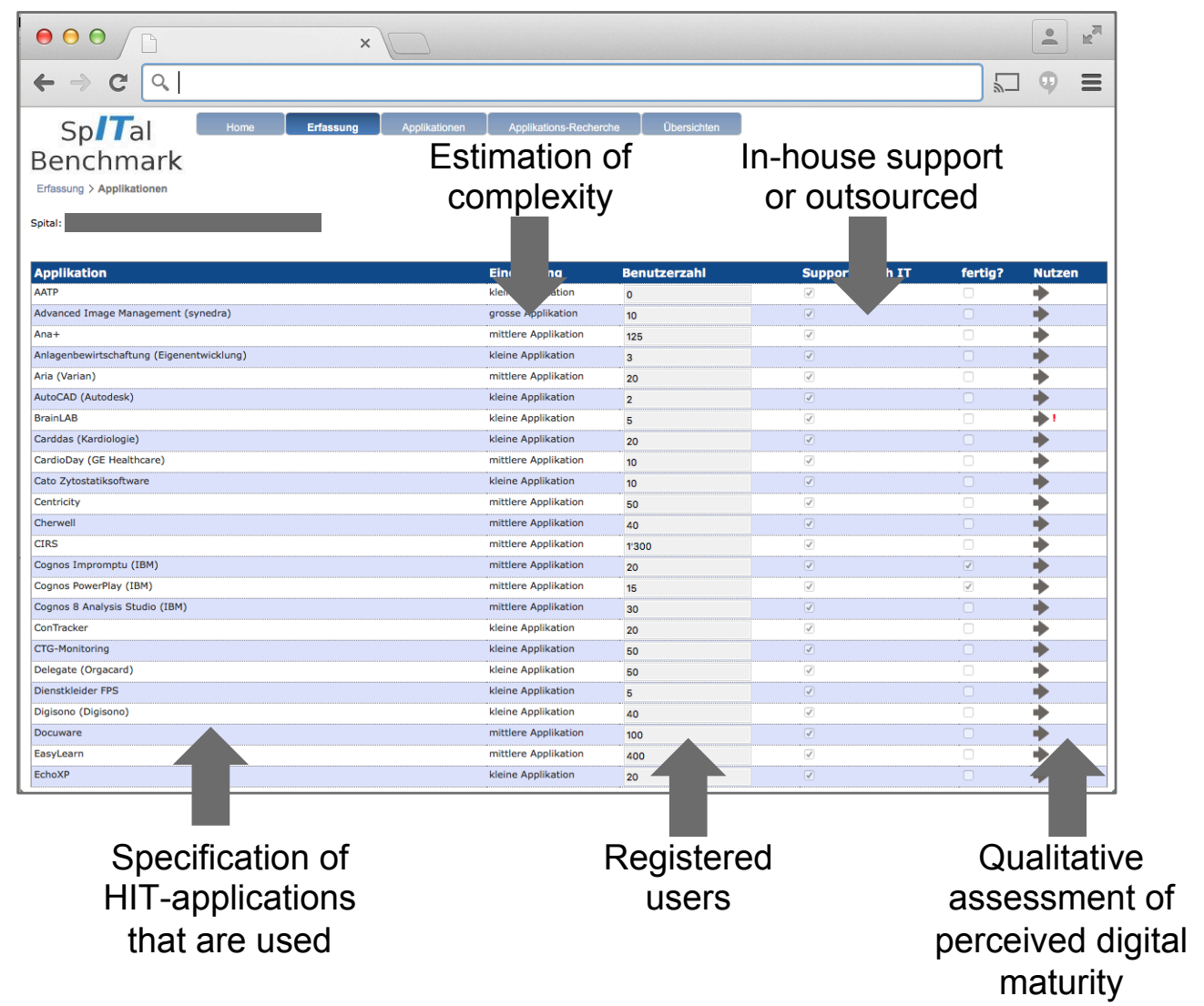

Figure D1. Input screen for entry of HIT-application parameters.

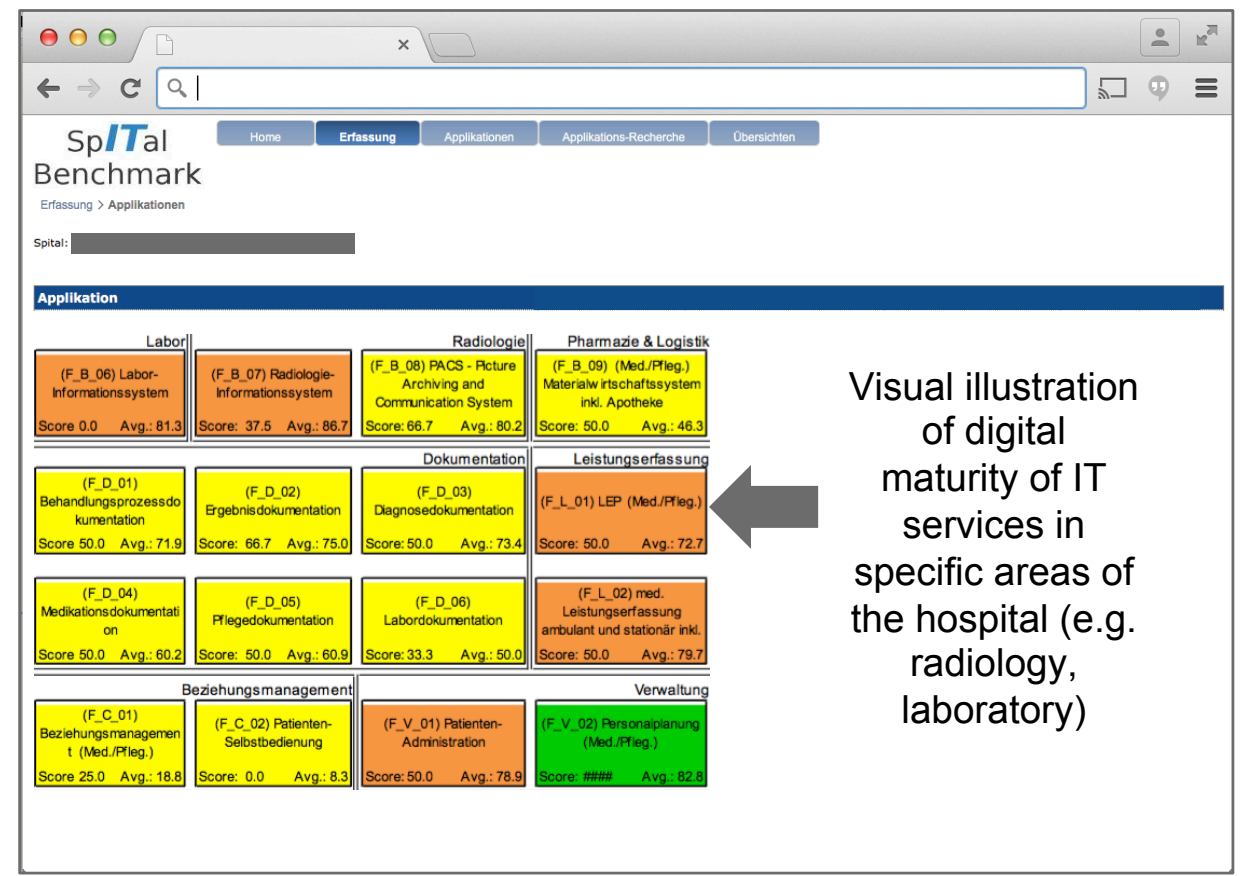

Figure D2. Output screen showing perceived digital maturity of a hospital. 